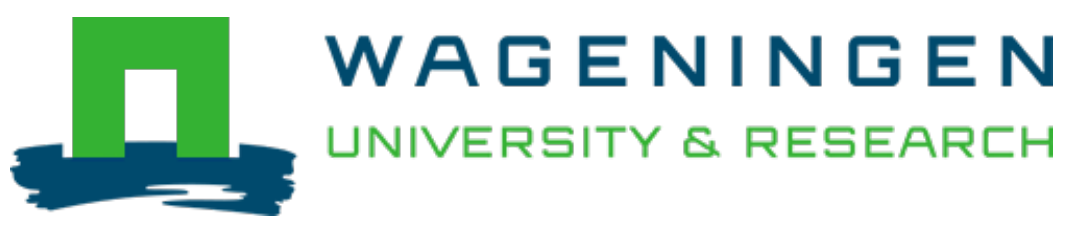

\title{
Contribution of selected fungi to the reduction of cyanogen levels during solid substrate fermentation of cassava.
}

International Journal of Food Microbiology

Essers, A.J.A.; Jurgens, C.M.G.A.; Nout, M.J.R.

https://doi.org/10.1016/0168-1605(94)00116-n

This publication is made publicly available in the institutional repository of Wageningen University and Research, under the terms of article $25 \mathrm{fa}$ of the Dutch Copyright Act, also known as the Amendment Taverne. This has been done with explicit consent by the author.

Article 25 fa states that the author of a short scientific work funded either wholly or partially by Dutch public funds is entitled to make that work publicly available for no consideration following a reasonable period of time after the work was first published, provided that clear reference is made to the source of the first publication of the work.

This publication is distributed under The Association of Universities in the Netherlands (VSNU) 'Article $25 \mathrm{fa}$ implementation' project. In this project research outputs of researchers employed by Dutch Universities that comply with the legal requirements of Article $25 \mathrm{fa}$ of the Dutch Copyright Act are distributed online and free of cost or other barriers in institutional repositories. Research outputs are distributed six months after their first online publication in the original published version and with proper attribution to the source of the original publication.

You are permitted to download and use the publication for personal purposes. All rights remain with the author(s) and / or copyright owner(s) of this work. Any use of the publication or parts of it other than authorised under article $25 \mathrm{fa}$ of the Dutch Copyright act is prohibited. Wageningen University \& Research and the author(s) of this publication shall not be held responsible or liable for any damages resulting from your (re)use of this publication.

For questions regarding the public availability of this publication please contact openscience.library@wur.nl 
Short Communication

\title{
Contribution of selected fungi to the reduction of cyanogen levels during solid substrate fermentation of cassava
}

\author{
A.J. Alexander Essers * , Carien M.G.A. Jurgens, M.J. Robert Nout \\ Department of Food Science, Section of Food Chemistry and Microbiology, \\ Wageningen Agricultural University, Bomenweg 2, 6703 HD Wageningen, The Netherlands
}

Received 25 February 1994; revision received 30 May 1994; accepted 8 August 1994

\begin{abstract}
The effect of six individual strains of the dominant microflora in solid substrate fermenting cassava on cyanogen levels was examined. Six out of eight batches of disinfected cassava root pieces were incubated for $72 \mathrm{~h}$ after inoculation with either of the fungi Geotrichum candidum, Mucor racemosus, Neurospora sitophila, Rhizopus oryzae and Rhizopus stolonifer, or a Bacillus sp., isolated from on-farm fermented cassava flours from Uganda. One non-inoculated batch was incubated as a reference. Levels of initial and final moisture and cyanogens were assayed. The experiment was done in quadruplicate.

Incubation of disinfected root pieces reduced cyanogenic glucoside levels significantly to $62.7 \%$ (SD 2.8) of the initial value. Microbial growth resulted in significant additional reduction of the cyanogenic glucoside levels to $29.8 \%$ (SD 18.9) of the levels which were obtained after non-inoculated incubation. Among the tested strains, $N$. sitophila reduced cyanogenic glucoside levels most effectively, followed by $R$. stolonifer and $R$. oryzae. Of all fermented samples, both Rhizopus spp. showed highest proportion of residual cyanogens in the cyanohydrin form. Flours showed similar patterns of cyanogens as the batches they were prepared from. Cyanogenic glucoside level reduction was significantly correlated $(r=0.86)$ with the extent of root softening.

It is concluded that both incubation and microbial activity are instrumental in reducing the potential toxicity of cassava during the solid substrate fermentation and that effectiveness varies considerably between the species of microorganisms applied.
\end{abstract}

Keywords: Cassava; Fungi; Bacillus; Solid substrate fermentation; Linamarin; Cyanogenic glucosides

\footnotetext{
* Corresponding author. Present address: Department of Toxicology, Wageningen Agricultural University, Tuinlaan 5, 6700 EA Wageningen, The Netherlands. Tel. 31-837085142. Fax 31-837084931. E-mail Sander.Essers@algemeen.tox.WAU.NL.
} 


\section{Introduction}

The tropical root crop cassava contains cyanogenic glucosides, which are potentially toxic. Cleavage of the glucosidic bond by the compartmentally separated enzyme linamarase, located in the cell wall, renders glucose and cyanohydrin (Mkpong et al., 1990). Cyanohydrins can be degraded enzymatically, but also decompose spontaneously at $\mathrm{pH}>5$ into acetone and the volatile HCN (Cooke, 1978). Toxicity of the latter is indicated by the estimated minimal lethal oral dose of $0.5-3.5 \mathrm{mg}$ per $\mathrm{kg}$ human body weight (Montgomery 1969). Cyanohydrins may decompose at the $\mathrm{pH}$ prevailing in the gut, yielding equal molar amounts of HCN. The toxicity of the glucosides is not yet well understood. Several health problems related to cyanogen uptake from insufficiently processed cassava have been reported from Africa (Rosling et al., 1993).

The required reduction of cyanogen levels before consumption is achieved by processing and preparation. A processing method applied in several parts of Africa includes a step of solid substrate fermentation (Essers et al., 1992, 1995, Gidamis, 1993). In Uganda (Essers et al., 1995) a common process is as follows: After superficial drying, the peeled roots are heaped and covered to incubate for 3 days to enable profuse mould growth. After removal of the fungal mycelium, crushing and sun-drying, the resulting crumbs are pounded into flour. Although the fermentation stage appeared functional in cyanogen removal, the contribution of the microflora remained unclear. Analyses of the microflora associated with this process in Uganda showed the frequent occurrence and abundance of several fungal species. The $\mathrm{pH}$ of the resulting flours was generally higher than 7 , in contrast with other fermented products from cassava (Vasconcelos et al., 1990, O'Brien et al., 1992).

The scope of this work is to study the contribution of several representative fungal and bacterial strains, isolated from Ugandan on-farm fermented cassava, to the changes in cyanogen levels by solid substrate fermentation. We examined whether incubation alone of disinfected cassava leads to reduction of the cyanogen levels; whether microbial growth leads to additional reduction of these levels; and whether effectiveness differs among micro-organisms.

\section{Materials and methods}

Disinfection of cassava pieces was required to suppress the outgrowth of microbial contamination, without hindering the intended growth of the inocculated strains, and without affecting the tissue structure. After preliminary comparison of options, the following procedure was selected. Cassava roots from Costa Rica were peeled and cut into $15 \mathrm{~g}$ pieces, using sterilised equipment. The pieces destined for fungal fermentation were submerged in oxytetracycline $(0.5 \mathrm{~g} / 1$ water $)$ for $60 \mathrm{~s}$, the ones for growth of bacteria in ethanol $(70 \% \mathrm{v} / \mathrm{v})$ for $60 \mathrm{~s}$, while the control batches 
were submitted to both treatments for $30 \mathrm{~s}$. Subsequently, the pieces were forced-air dried at $55^{\circ} \mathrm{C}$ for $1.5-2 \mathrm{~h}$, to reach a moisture content of $55-60 \%$.

Inoculation was similar for all microbial cultures and was carried out by pressing thus pre-treated root pieces directly on plates overgrown with pure cultures of

Table 1

Levels of cyanogenic glucosides and cyanohydrins in moist cassava and their flours, and softness, after different treatments in the four experimental blocks

\begin{tabular}{|c|c|c|c|c|c|}
\hline \multirow{3}{*}{$\begin{array}{l}\text { Treat- } \\
\text { ment }\end{array}$} & \multicolumn{2}{|c|}{ Moist cassava } & \multicolumn{2}{|l|}{ Flours } & \multirow{3}{*}{$\begin{array}{l}\text { Soft- } \\
\text { ness }\end{array}$} \\
\hline & \multicolumn{4}{|c|}{ 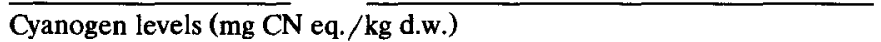 } & \\
\hline & CN-gluc. & Cyanoh. & Cyanogenic glucosides & Cyanohydrins & \\
\hline 1 & 92.7 & 10.3 & 46.6 & 5.4 & 0 \\
\hline 2 & 60.5 & 4.0 & 39.8 & 2.1 & 1 \\
\hline 3 & 26.3 & 15.3 & 14.7 & 2.5 & 2 \\
\hline 4 & 25.1 & 11.7 & 15.2 & 1.6 & 2 \\
\hline 5 & 3.4 & 1.5 & 1.4 & 0.2 & 5 \\
\hline 6 & 12.1 & 43.1 & 14.7 & 10.8 & 5 \\
\hline 7 & 11.7 & 33.8 & 2.0 & 1.7 & 5 \\
\hline 8 & 14.8 & 40.8 & 8.4 & 0.9 & 3 \\
\hline 1 & 209.9 & 16.4 & 79.5 & 6.3 & 0 \\
\hline 2 & 123.3 & 3.4 & 68.5 & 1.9 & 0 \\
\hline 3 & 62.9 & 15.7 & 32.6 & 3.3 & 2 \\
\hline 4 & 81.9 & 2.0 & 41.0 & 2.0 & 1 \\
\hline 5 & 14.9 & 1.4 & 22.0 & 0.9 & 4 \\
\hline 6 & 24.1 & 42.2 & 22.8 & 17.2 & 5 \\
\hline 7 & 19.9 & 44.2 & 4.2 & 1.1 & 5 \\
\hline 8 & 44.0 & 48.2 & 29.9 & 2.5 & 3 \\
\hline 1 & 219.3 & 6.1 & 108.0 & 15.6 & 0 \\
\hline 2 & 138.1 & 49.4 & 86.7 & 5.1 & 1 \\
\hline 3 & 48.2 & 9.4 & 37.7 & 2.6 & 2 \\
\hline 4 & 53.6 & 22.8 & 30.0 & 3.1 & 2 \\
\hline 5 & 3.6 & 0.7 & 7.2 & 0.7 & 4 \\
\hline 6 & 15.0 & 59.0 & 31.4 & 8.5 & 5 \\
\hline 7 & 11.5 & 71.6 & 11.7 & 4.7 & 5 \\
\hline 8 & 65.3 & 77.6 & 17.9 & 3.3 & 2 \\
\hline 1 & 321.5 & 6.5 & 120.9 & 10.9 & 0 \\
\hline 2 & 204.6 & 43.3 & 107.1 & 4.3 & 1 \\
\hline 3 & 101.6 & 8.9 & 46.6 & 4.0 & 2 \\
\hline 4 & 112.1 & 14.1 & 63.5 & 2.6 & 2 \\
\hline 5 & 27.2 & 4.6 & $-c$ & 1.6 & 3 \\
\hline 6 & 45.5 & 64.5 & 31.2 & 14.9 & 5 \\
\hline 7 & 31.6 & 86.1 & 12.1 & 4.3 & 5 \\
\hline 8 & 127.8 & 86.5 & 44.6 & 9.3 & 2 \\
\hline
\end{tabular}

a Treatments: 1 Control $t=0 \mathrm{~h}, 2$ Control $t=72 \mathrm{~h}, 3-8$ are incubated for $72 \mathrm{~h}$ with: 3 Geotrichum candidum, 4 Mucor racemosus, 5 Neurospora sitophila, 6 Rhizopus oryzae, 7 Rhizopus stolonifer, 8 Bacillus sp.

${ }^{\mathrm{b}} 0=$ no softening, $5=$ completely soft.

c Not examined. 
micro-organisms isolated by the authors from traditionally heap-fermented cassava in Kiryandongo village, Masindi district, in rural Uganda (Essers et al., 1995). Filamentous fungi, identified on the basis of their macro- and microscopic morphology according to Samson and Van Reenen Hoekstra (1988), and a Gram-positive endospore-forming rod-shaped bacterium classified as Bacillus sp., not further identified, were deposited in the culture collection of the Department of Food Science of Wageningen Agricultural University (LU). These included the fungi Geotrichum candidum (LU243), Mucor racemosus (LU360), Neurospora sitophila (LU420), Rhizopus oryzae (LU582) and Rhizopus stolonifer (LU590) which were cultured on Malt Extract Agar, Oxoid CM59, and a Bacillus sp. (LU809) which was cultured on Nutrient Agar, Oxoid CM3. Incubation was in sterilised jars of 720 $\mathrm{ml}$ during $72 \mathrm{~h}$ at $25^{\circ} \mathrm{C}$. Screw-caps were left open to avoid anaerobiosis.

Extraction and analysis of the cyanogenic compounds was by homogenisation of about $70 \mathrm{~g}$ in $250 \mathrm{ml} 0.1 \mathrm{M}$ orthophosphoric acid, followed by conversion to HCN, which was measured spectrophotometrically after coloration (Essers et al., 1993).

Peeled cassava roots were cut into $1.5 \mathrm{~cm}$ thick discs, which were split into several segments, having near to equal cyanogen levels (De Bruijn, 1971). The adjacent segments were matched to obtain eight batches of about $350 \mathrm{~g}$ with similar cyanogen levels. After disinfection pre-treatment, from one batch four sub-samples were taken and extracted immediately $(t=0)$ to serve as a reference for the cyanogen content; one non-inoculated batch and six batches inoculated with either of the microorganisms mentioned above were incubated for $72 \mathrm{~h}$ at $25^{\circ} \mathrm{C}$. Treatment codes are shown in Table 1 . After these treatments, a part of each batch was processed into flour by oven-drying at $55^{\circ} \mathrm{C}$ for one day and subsequent milling (Fritsch Pulverisette type 14.702, Laborgeschaft, Idar-Oberstein, Germany) through sieves of, subsequently, 4 and $1 \mathrm{~mm}$. Extraction and subsequent analysis for cyanogens took place immediately after incubation and after flour preparation.

Specificity of microbial growth was evaluated macroscopically and by characteristic odour of the fermenting products. The extent of growth was monitored semi-quantitatively, using a subjective classification scale from 0 (no visible growth) to five (completely covered). Quantitative measurement of fungal propagules was omitted, as this would mainly refer to sporulation of the fungi and not to the more relevant mycelial growth and physiological activity (Nout et al., 1987). Extent of softening of the root pieces was classified on a scale from 0 (no softening) to five (completely soft) after manually probing with a round tipped $3 \mathrm{~mm} \emptyset$ glass bar.

The experiment was carried out four times with intervals of one week.

Treatment effects were judged with the Protected Least Significant Difference method (PSD) (Snedecor and Cochran, 1980, p. 234). First, the overall treatment effect was examined by an $F$-test in a two-way analysis of variance with $7 \mathrm{df}$ for treatments and 21 for residuals. In case of a significant $F$, the differences between treatment effects were tested by $t$-test (Snedecor and Cochran, 1980). In order to stabilize the variance, a logarithmic transformation of the cyanogenic glucoside values was applied, to differentiate between low residual levels.

Significance of differences are related to two-tailed probability $(p)$ values. 


\section{Results and discussion}

Microbial growth was good in the inoculated batches and nearly absent in the non-inoculated ones. Table 1 presents the absolute data on residual cyanogen levels, as well as the softening, in the moist cassava batches and their flours. The $\mathrm{pH}$ was significantly reduced $(p<0.0001)$ to 4.8 (SD 0.5$)$ after fermentation by Rhizopus oryzae, but remained at 6.7 (SD 0.2) after the other treatments (results not shown).

Cyanogenic glucoside levels after incubation only (treatment 2 ) were significantly lower than those of fresh roots (treatment 1 ), with $p<0.0001$ for the moist products and $p=0.001$ for the flours, indicating that incubation alone led to reduction of cyanogenic glucoside levels. The cause of this decrease is probably associated with the physiological deterioration of the cell wall and membrane structure (Padmaja and Balagopal, 1985) which, by leaking, allow contact between endogenous linamarase and the cyanogenic glucosides, resulting in breakdown of the latter.

Cyanogenic glucoside levels in moist products and flours from batches that were incubated after inoculation (treatments 3 to 8 ) were significantly lower $(p<0.0001)$ than samples after incubation only (treatment 2 ), indicating an additional effect of the microflora. The effect may have been caused by increased endogenous linamarase-linamarin contact through disintegration of cell wall and membrane structures, or by introducing additional microbial linamarase, or by both.

The effects from the microbial species (treatments 3 to 8 ) on cyanogenic glucoside levels could be differentiated statistically $(p<0.05$, PSD) as follows: $N$. sitophila fermented batches had lowest levels, followed by the Rhizopus spp. and the Bacillus sp. Of the flours, $R$. stolonifer and $N$. sitophila fermented batches had significantly lower $(p<0.05)$ cyanogenic glucoside levels than the others.

The level of cyanohydrins, as well as their proportion of total cyanogens, was significantly different $(p<0.0001)$ after the different treatments, both for moist products and flours. These levels and proportions were significantly higher $(p<$ $0.05, \mathrm{PSD}$ ) in the $R$. oryzae, $R$. stolonifer and Bacillus sp. fermented batches than in the others, and after drying remained significantly higher in the flour from the $R$. oryzae fermented cassava. As the loss of the cyanogenic glucosides in this process is through the stage of cyanohydrins, these compounds were apparently better preserved in these last three fermented products. As cyanohydrins are more stable at a lower $\mathrm{pH}$ (Cooke, 1978), the higher level of cyanohydrins and their proportion of total cyanogens in the $R$. oryzae fermented products may be explained by the lower $\mathrm{pH}$ attained by that fermentation. We cannot explain the high cyanohydrin to total cyanogen ratios in the $R$. stolonifer and Bacillus $\mathrm{sp}$. fermented batches.

$\mathrm{HCN}$ levels in the moist products ranged from $0.1-5.7 \mathrm{mg} \mathrm{CN}$ equivalent per $\mathrm{kg}$ dry weight with a mean of 2.1 (SD 1.7, $n=32$ ). In the flours, these levels did not exceed $2.0 \mathrm{mg} \mathrm{CN}$ equivalent per $\mathrm{kg}$ dry weight. The sum of cyanohydrins and $\mathrm{HCN}$ in each flour sample was below $10 \mathrm{mg} \mathrm{CN}$ equivalent per $\mathrm{kg}$ dry weight. These low levels are explained by the rigorous final drying step leading to moisture 
levels of about 5\%. It has been observed earlier by Banea et al., (1992) that cyanohydrins are lost at low moisture levels.

The treatments had a significant effect $(p<0.0001)$ on the softness of the products. Softening of the pieces was most advanced ( $p<0.05$, PSD) after fermentation by the Rhizopus spp., followed by Neurospora. Geotrichum, Mucor and Bacillus only caused superficial softening (Table 1). In moist products and flours, residual cyanogenic glucoside levels differed significantly $(p<0.0001)$ among the softness classes of the fermented root pieces. The reduction in glucoside levels was significantly correlated $(r=0.86)$ with the extent of root softening. Comparing the $F$ values for treatments and softness in moist products after correcting each for the effect of the other, the effect of treatment $(p=0.003)$ and softness $(p=0.035)$ on the glucoside levels remained significant. For flours, the treatment effect remained significant ( $p=0.0003$ ) after correction for softness of the moist products, but the effect of softness on the residual glucoside levels just lost significance ( $p=0.102$ ) after correcting for treatment effect. These findings indicate that treatment is more powerful than softness for explaining the glucoside level reduction.

The cyanohydrin proportion of total cyanogens in the moist products was significantly related $(p<0.0001)$ and correlated $(r=0.73)$ to softness after fermentation, but not in the flours. The sequence suggested that the softer the product, the higher this proportion, except for $N$. sitophila fermented cassava. Also here, it appears that although softening has a substantial effect on the cyanohydrin proportion, it does not fully explain the treatment effect.

Softness or structure loss of cassava tissue was induced by the treatments. The fact that correction for the treatment effect reduced the statistical significance of the softness effect on the glucoside levels and cyanohydrins to total cyanogens ratio's far more than vice versa, indicates that treatment as such is a stronger determining factor than softness only. It is likely that, in addition to the extent of structure loss, also the type of cell wall and membrane structure degradation is of importance. The possibility of an additional effect from microbial linamarase activity can not be excluded. Okafor and Ejiofor (1986) found a cyanogen lowering effect from microorganisms that were selected for their linamarase capacity, when seeded on fresh pulp. Maduagwu (1983) and Vasconselos et al. (1990) found no such effect in spontaneous fermenting cassava pulp. In the latter cases, the major part may already have been hydrolysed by endogenous enzyme liberated by the cell disruption, before the relevant microorganisms were in sufficient number to cause significant effect. Neither of those studies compare to the present experiment, however, as here no mechanical disruption occurred to liberate the endogenous linamarase. The mechanisms of the microflora bringing about the linamarin level reduction in these experiments is subject of further study.

Although the culture conditions during these experiments were made to resemble average in situ conditions, the growth and enzyme production of these micro organisms may be favoured differently according to the environmental conditions at household level.

Concluding, we found that both incubation and microbial growth were instru- 
mental in reducing cyanogenic glucoside levels and changing cyanogen composition in cassava root pieces. The effectiveness differed between the species of microorganisms and was also associated with the root softening obtained. From the perspective of reducing cassava's potential toxicity, $N$. sitophila was most successful, followed by $R$. stolonifer and $R$. oryzae.

\section{Acknowledgements}

This study was financed by the Netherlands' Minister for Development Co-operation.

\section{References}

Banea, M., Poulter, N.H. and Rosling, H. (1992) Shortcuts in cassava processing and risk of dietary cyanide exposure in Zaire. Food Nutr. Bull. 14, 137-143.

Cooke R.D. (1978) An enzymatic assay for the total cyanide content of cassava (Manihot esculenta Crantz). J. Sci. Food Agric. 29, 345-352.

Essers, A.J.A., Alsen, P. and Rosling, H. (1992) Insufficient processing of cassava induced acute intoxications and the paralytic disease konzo in a rural area of Mozambique. Ecol. Food Nutr. 27, $17-27$.

Essers, A.J.A., Bosveld, M., Grift, R.M. van der, and Voragen, A.G.J. (1993) Studies on the quantification of specific cyanogens in cassava products and introduction of a new chromogen. J. Sci. Food Agric. 63, 287-296.

Essers, A.J.A., Ebong, C., Grift, R.M. van der, Nout, M.J.R., Otim-Nape, W. and Rosling, H. (1995) Reducing cassava toxicity by heap-fermentation in Uganda. Int. J. Food Sci. Nutr. 46, 125-136.

Gidamis, A.B., O'Brien, G.M. and Poulter, N.H. (1993) Cassava detoxification of traditional Tanzanian cassava foods. Int. J. Food Sci. Tech. 28, 211-218.

Maduagwu, E.N. (1983) Differential effects on the cyanogenic glycoside content of fermenting cassava root pulp by beta-glucosidase and microbial activities. Toxicol. Lett. 15, 335-339.

Mkpong, O., Hua-Yan, E., Chism, G. and Sayre, R.T. (1990) Purification, characterization and location of linamarase in cassava. Plant Physiol. 93, 176-181.

Montgomery, R.D. (1969) Cyanogenic Glycosides. In: Liener (editor), Toxic Constituents of Plant Foodstuffs. Academic Press, New York, NY, pp. 143-157.

Nout, M.J.R., Bonants-Van Laarhoven, T.M.G., De Jongh, P. and De Koster, P.G. (1987) Ergosterol content of Rhizopus oligosporus NRRL 5905 grown in liquid and solid substrates. Appl. Microbiol. Biotechnol. 26, 456-461.

O'Brien, G.M., Mbome, L., Taylor, A.J. and Poulter, N.H. (1992) Variations in cyanogen content of cassava during village processing in Cameroon. Food Chem. 44, 131-136.

Okafor, N. and Ejiofor, M.A.N. (1986) The microbial breakdown of linamarin in fermenting pulp of cassava (Manihot esculenta Crantz). MIRCEN J. 2, 327-338,

Padmaja, G. and Balagopal, C. (1985) Cellular and extracellular enzymes associated with the post harvest deterioration of cassava tubers. J. Food Sci. Technol. 22, 82-87.

Rosling, H., Mlingi, N., Tylleskär, T. and Banea, M. (1993) Causal mechanisms behind human diseases induced by cyanide exposure from cassava. In: W.N. Roca and A.M. Thro (editors), Proceedings from the first meeting of the Cassava Biotechnology Network, Cartagen, Colombia, 25-28 August 1992. CIAT. Cali, Colombia.

Snedecor, G.W. and Cochran, W.G. (1980) Statistical Methods, 7th edn. Iowa State University Press, Iowa, USA, $507 \mathrm{pp.}$

Vasconcelos, A.T., Twiddy, D.R., Westby, A. and Reilly, P.J.A. (1990) Detoxification of cassava during gari preparation. Int. J. Food Sci. Tech. 25, 198-203. 